\title{
When does stacking become vertical sprawl?
}

\author{
I. S. Y. Hwang ${ }^{1,2}$ \\ ${ }^{1}$ The University of Sydney, Australia \\ ${ }^{2}$ The University of Hong Kong, Hong Kong, People's Republic of China
}

\begin{abstract}
More cities are expanding and aspiring to expand vertically. Many are advocating densification/intensification as a sustainable alternative to the urban sprawl of the west. Is densification the cure-all snake oil to problems associated with endless sprawl and leap-frog suburbia?

This paper uses Hong Kong - one of the most dense cities in the world - to discuss whether the vertical city is a sustainable solution to human settlements. Like any other concept and theory, the implementation requires a much deeper and comprehensive understanding of the process of actualisation. Without this process, instead of a leap-frog suburb, a skyscraping suburb will be created, instead of the automobile, people will be highly dependent on elevators and escalators and most importantly, this may have already started to occur in cities around the world. This paper discusses the difference between stacking and vertical sprawl and examines the notion of the vertical sprawl through examples of the vertical cul-de-sacs and vertical gated communities already existing in Hong Kong and calls for more rigour in approaching densification.

Keywords: vertical sprawl, stacking, cul-de-sac, gated communities, urban expansion, high-rise, high density, compact city.
\end{abstract}

\section{Introduction}

Sustainability has been 'the topic' across all disciplines over the last few decades. People in business, politics, science, anthropology talk about it and it is probably one of the most used, abused and misused words of this century. Discussions on cities are not an exception. It is impossible to find a book on cities or urbanism which does not mention the word 'sustainable' or 'sustainability' once. This indicates the importance and hence the appropriate attention given to the issue of sustainability in the discussion of cities. In the 
discussion of sustainable cities, densification is often presented as a sustainable alternative as traumatic lessons are learned from the urban sprawl of the west. Mau asks the world to stack its population vertically and describes densification as a sustainable solution as it will "simultaneously open up the surrounding rural space" [1].

Today cities are expanding in all possible directions to satisfy increasing populations as well as to accommodate for the demand of different life styles etc. In many places with an abundance of land such as the USA and Australia, cities generally expand horizontally resulting in strings of leap-frog suburbia along the city's main arterial roads and therefore increasing the need for private vehicle. For instance, in $2002,70.2 \%$ of people travelling to their place of employment or study in New South Wales, Australia, commuted by private vehicle [2]. There is also a demand for a second car at home as any services are far from walking distance. This high automobile dependency is well documented in works of Newman and Kenworthy [3,4]. Along with the high vehicle dependency, authorities are also accounting various social issues as well as greater pressure for the provision of adequate infrastructure and amenities. These suburbs are continuing to appear with new street names and addresses in Sydney and the fire brigade service is not aware of new developments as street directories are only updated once a year. As ridiculous as this may sound, this demonstrates the seriousness of the endless sprawl and the related costs. With the increasing pressure from all sides, the NSW State Government of Australia has outlined to contain $60-70 \%$ of future housing developments within established areas in the Metropolitan Strategy, looking into intensification as a solution [5].

On the other hand, cities with clear physical limits of available land such as Hong Kong has been practicing a different approach to planning and development resulting in the skyline of incredible density and verticality. As more cities grow taller and denser, more airspace is being occupied and inhabited, yet most infrastructures and interaction facilitators remain on or near the ground plane with many repeated equal floor plates containing a single program. Although many Australian and American cities are resorting to intensification to remedy the sprawl cost, many do not realised that the equal and often non-desirable conditions of conventional horizontal sprawl can easily translate to the vertical version. The automobile dependency and conventional cul-de-sacs of the horizontal version equate to the elevator/escalator dependence and vertical cul-de-sacs of the tower version in the central cores. Usual horizontal gated communities are stacked vertically occupying a smaller footprint, but huge airspace vertically. With a series of cul-de-sac towers and vertical gated community developments, a vertical sprawl is established.

Like any other translation, it is natural for certain mutations to occur from the horizontal to the vertical version. Therefore, a more fundamental evaluation of the nature of cul-de-sacs and gated communities are required rather than assuming it to exist only in the context of sprawling residential developments. This evaluation leads to the translation of the concept of 'cul-de-sac' and 'gated communities' into other types of buildings and developments not usually associated with it. This paper will discuss vertical sprawl typology of vertical 
gated communities and vertical cul-de-sac through examples in Hong Kong and evaluate whether the direction of vertical cities undertook in Hong Kong is a sustainable solution.

\section{When stacking becomes vertical sprawl}

In recent years, the stacking of diverse programs has been tirelessly experimented by MVRDV. One of their earliest attempts is Berlin Voids in 1991. Adam describes the idea of stacking employed in this project as "not a stereotype multistoried apartment block in the tradition of post-war modernism, but rather a three-dimensional puzzle of diverse types of flats interspersed with holes, empty spaces and public spaces" [6]. One of the few built projects of MVRDV's radical stacking concept is the Dutch Pavilion for the Expo 2000 designed in 1997 which is a "stacked landscape" of nature in an unmistakeably artificial way [6]. This vertical stacking is further studied through projects such as the Museum of Primitive Arts Quai Branly, LNV New Office of the Ministry of Agriculture, 3D City [7, 8]. Attali describes the work of MVRDV as follows:

"MVRDV imagines its buildings in cross-section and erects them like vertical labyrinths...Its entangled pathways communicate among themselves, even if they lead mostly to dead ends. Passageways and doors proliferate, but the number of exits is severely restricted. Why not, then imagine a labyrinth into the third dimension? Why not shift the paradigm?'[9]

Due to the severe shortage of land and ever growing population, Hong Kong is no stranger to the practice of stacking in all facets of life. Double-decker buses are becoming more a 'Hong Kong Thing' rather than its original British counterpart. Wet markets are stacked with different produce organised on different levels, teenagers go up to the roof of their school building to play basketball and even dim sums are served in stacked bamboo steamers. Stacking has been the predominant way of making and duplicating space in Hong Kong and at one point, stacking in building has became vertical sprawl. In the name of economies of scale and efficiency, many countries, through modernization, have competitively produced housing estates with the capacity to house thousands of households equipped with obligatory amenity facilities to satisfy basic shopping and recreational needs. According to Karakiewicz, Mei Fu Sun Chuen Estate (the first private housing development in Hong Kong) used the typical shop house typology where living takes place above the working space, with multiple living spaces above, therefore, distorting the proportion between commercial and residential activities [10]. Today, it is typical for housing developments in Hong Kong to have 25-27 storey residential towers on top of a podium structure containing shopping, parking and laundry etc. As towers grow taller, the proportion between living and working is further skewed and "becomes progressively detached from the city" [10].

Adam, in the abovementioned description of Berlin Voids, suggests a distinct difference between the idea employed by MVRDV and that of the traditional housing developments - the difference between stacking and vertical sprawl [6]. 
Stacking of mixed programs invites opportunities for interactions and these opportunities are accommodated in public spaces provided within the structure. However, in vertical sprawl structure, while mixed use gesture maybe made on or near ground level, the structure is largely made of repeated floor plates which contain single or similar programs. In a vertical city like Hong Kong, the existing zoning-oriented planning approach almost guarantees to produce a vertical sprawl rather than an integrated intelligent stacking of programs. While the vertical sprawl in Hong Kong may consume less than $20 \%$ of its land as built area (therefore economically and environmentally sustainable), it still has outstanding issues of achieving social sustainability [10].

\section{Gated communities and cul-de-sacs}

It has to be reinforced at this point that the concepts of gated communities and cul-de-sacs are not exclusively tied to the horizontal manifestation. In the vertical version, due to its inherent nature of intentional disconnectedness from activities and interaction, both gated communities and cul-de-sacs constitutes vertical sprawl rather than the intelligent stacking of MVRDV.

The concepts of gated communities and cul-de-sacs share many common characteristics and therefore make the differentiation between the two very difficult and ambiguous processes. While gated communities are, by nature a type of cul-de-sac, smaller cul-de-sacs can also be formed within a physical boundary of gated communities. For the purpose of this paper, in the following sections, the distinction between gated communities and the cul-de-sac is made by simply determining whether the access is open to non-residents/non-tenants or not. Gated communities have a controlled, usually single point of access where non-residents is prohibited to enter. Visitors to residents of gated communities are scrutinized and checked where as access to a cul-de-sac is open to public while strangers present in cul-de-sac settings are carefully watched.

Similarly this different level of security and control also impacts a community's potential to expand. A cul-de-sac has potential for much more organic communities than gated communities. While both layouts encourage the formation of communities, cul-de-sacs have a capacity to expand and accommodate other non-residents into their communities. In other words, others will be welcomed and not be watched like a stranger if he/she lives two streets down and have been accepted into the cul-de-sac neighbourhood, whereas regardless of one's familiarity with the community or residents, he/she will be subjected to the standard security procedure during every visit. When it comes to the capacity to expand its neighbourhood, a vertical cul-de-sac is more inorganic than its horizontal counterpart. As a vertical cul-de-sac development is highly internalised and strictly defined by its outer façade, it does not have a capacity to expand its community nor allow any parasite new-comers.

While acknowledging that most of cul-de-sacs and gated developments are residential, it is important to broaden one's understanding and realise the nonresidential cul-de-sacs and gated developments do exist. For instance, industrial parks in many Australian and American cities are gated communities where a 
number of commercial tenants share a common security and other amenity services. Similarly, non-closed industrial parks where similar industries congregate around one area such as Silicon Valley in the USA is a nonresidential cul-de-sac development.

\section{Vertical gated community}

Blakely and Snyder limits gated communities to residential developments in their definition as follows:

“... residential areas with restricted access in which normally public spaces are privatised. They are security developments with designated perimeters, usually walls or fences, and controlled entrances that are intended to prevent penetration by nonresidents" [11].

While the most gated communities are spread-out residential developments, in this day of heightened security and surveillance, more and more commercial and office buildings are taking the same approach to gated communities. Burke briefly discusses secure apartment complex as a type of gated communities and hence alludes multi-level buildings to be included in the categories of gated communities [12]. Dovey takes a more holistic approach to the tower as an enclave development and that "a vertical enclave" becomes increasingly detached from the city [13]. He continues to argue when coupled with parking facilities on ground floor, it will discourage movement and reduce "the need to use the street for access and thereby weakening the safety component of streetlife vitality" [13]. For instance, the International Finance Centre One (IFC One) tower in Hong Kong is an example of a gated office tower. In order to enter the building which houses many security-sensitive tenants such as the Hong Kong Monetary Funds, on top of the usual security measures - numerous surveillance cameras and security guards around the clock - one has to use his/her security pass to enter into the elevator lobby under the watchful eyes of security guards and surveillance cameras. For this reason, it may be more suitable to call it 'enclave development' which is inclusive of any program rather than limiting to residential development. However, most office towers in Hong Kong are not gated while they are equipped with the usual security guards and surveillance cameras. Therefore most examples of vertical gated communities are residential buildings. It is typical for residential developments in Hong Kong to have 24hour security guards who restrict entries by non-residents.

\subsection{Tai Koo Shing: vertical gated community}

Tai Koo Shing development is a residential development situated in the eastern end of Hong Kong Island, facing the Victoria Harbour of Hong Kong. The development contains approximately 48,000 people in 13,800 units occupying a footprint of 956,000 square meters with a plot ratio of approximately 4.5:1 [14]. It is clear that the area was planned and designed as a fully serviced, selfcontained development equipped with a shopping centre, sports facilities, schools and other facilities as well as office towers. Tai Koo Shing is connected 
to the Island Line of MTR (Hong Kong's subway system) through Tai Koo Shing Station which is located at the centre of the development. All other forms of public transportation - trams, buses and mini buses - are diverted to its periphery, as only vehicular traffic allowed through the development is private automobiles or taxies. Most travel out of Tai Koo Shing is done by MTR, however, Tai Koo Shing is, as intended, an island, where "you can live, work, shop and entertain yourself without stepping out of the development" [14].

The majority of the apartment towers stand on top of podium structures which reinforce the street pattern on the ground. The largest podium contains City Plaza - a shopping complex with connection to MTR with many other podium structures containing a car park, small shops and public plaza. Floor plates are repeated from level 1 to level 28 and residential units are disconnected from the street and podium level resulting in a largely deserted public plaza on the podium level. Tai Koo Shing is a good example of mixed use development which eventuated in the vertical sprawl consists of a series of vertical gated communities.

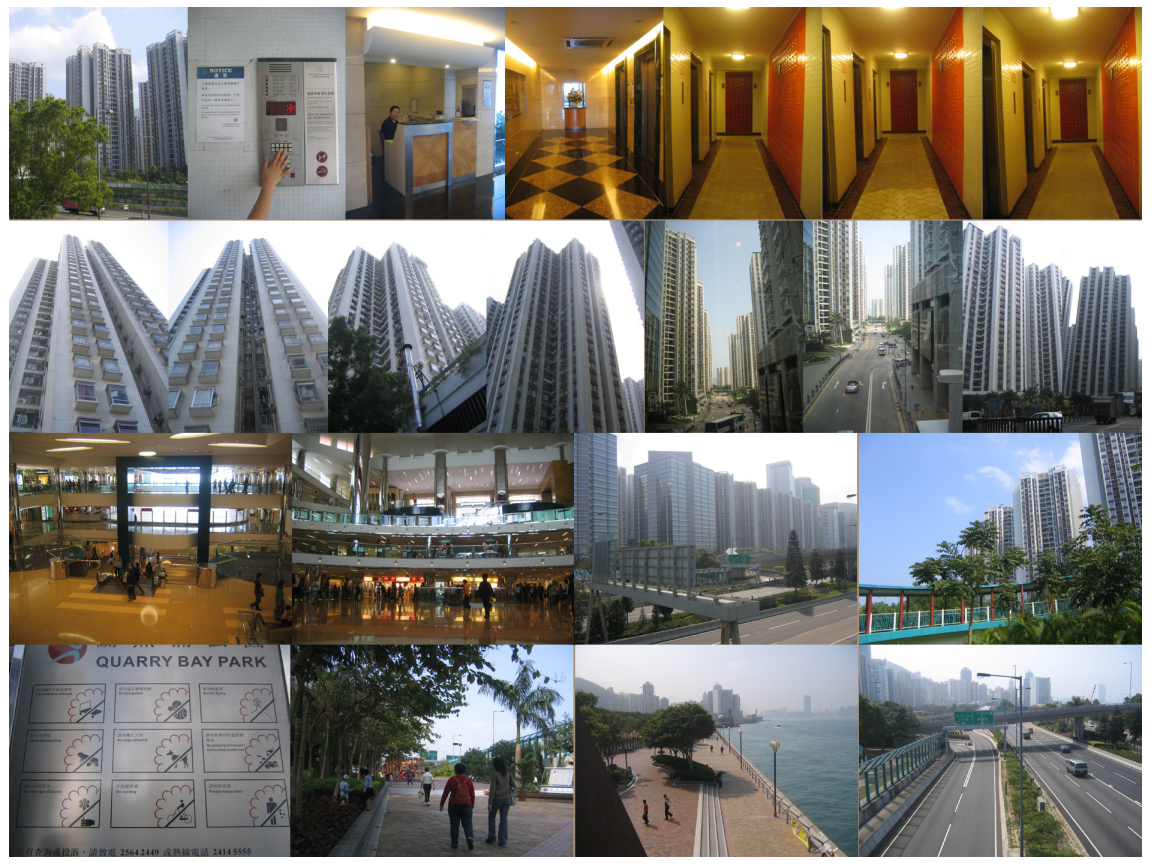

Figure 1: $\quad$ Tai Koo Shing.

Despite the close proximity to the rest of the city and the vertical nature of its physical manifestation, the planning concept is almost identical to that of a suburb. A shopping centre, where most daily consumptions are satisfied is at the centre of the development, equivalent to the town centre of Sydney's suburbs. The shopping centre dully functions as a transportation hub as it connects to Tai 
Koo Shing MTR Station. Apartment towers possess an identical exterior which also corresponds to consistent area development of outdoor spaces. Many of the New Town developments of Hong Kong also take a similar form of large housing development with consistent exterior with shopping centre /transportation hub which contains train station as well as bus terminus.

The development contains a series of gated towers forming vertical residential enclaves, which are equipped with 24-hour security guards and surveillance cameras. Residents can tune into a specific channel on their TV to view elevator lobby, elevator and entry lobby through the lens of surveillance cameras in real time. The development's communal sporting and other recreational facilities are scattered around between gated towers with streets and outdoor space open to non-residents' use. The development therefore is a series of gated residential towers with communal facilities with varying degrees of exclusivity in view of non-residents, and hence categorised here as a 'vertical gated community'.

\section{Vertical cul-de-sac}

Whittick simply defines the cul-de-sac as "a street closed at one end" and may be "T-shaped, circular, square, hexagonal. Elliptical, rectangular, or other geometric shape; and they may be of various sizes" [15] while Dovey defines the suburban cul-de-sac as "where the ideal is that of a like-minded community, protected from through traffic, surrounding a shared space where strangers will be noticed and watched" [13]. The presence of strangers must be noted which is generally not allowed in gated communities. The suburban cul-de-sac usually terminates with a large open space which may be a garden or square where children can play safely away from high-speed traffic. This large open space at the end of a cul-de-sac is seen as an activity and encounter facilitator. It is for this perceived sense of safety why many prefer cul-de-sac developments as a family-friendly environment. This sense of community which a typical layout of conventional cul-de-sac suggests is one of the reasons why cul-de-sac developments are widely popular and this public's warmth towards the cul-de-sac is well depicted in mass media where despite the wide condemnation from academia, cul-de-sac developments are portrayed as a positive family-friendly neighbourhood.

Although it is true that most cul-de-sac developments took place as residential developments in horizontal form, the concept of cul-de-sac shall not be limited to that of a horizontal residential development. While many do not realise, vertical cul-de-sac towers are in every city. Internalised office towers with repeated floor plates of the identical program constitute a vertical cul-de-sac. Some may terminate without activity/encounter facilitator, as it will be another floor of office while some may contain different functions such as a restaurant, bar or even a gym.

\subsection{Exchange Square Two: vertical cul-de-sac}

Exchange Square Two is a commercial tower located in Central, Hong Kong, connected to the Mass Transit Railway (MTR) Central Station as well as Hong 
Kong Airport Express Line. Exchange Square Two is part of the greater Exchange Square Development which consists of the podium building with the large public plaza on top levelled with the elevated walkway, three separate towers - 52 and 51,33-storey high respectively - and one 3-storey small amenities building. The podium building contains a bus terminus for large double-decker buses as well as mini 16-seater buses. 51 levels of Exchange Square Two range from 12,000 sq. $\mathrm{ft}$ in the low zone to $13,900 \mathrm{sq} . \mathrm{ft}$ in the high zone serviced by 22 passenger lifts and 2 service lifts [16].

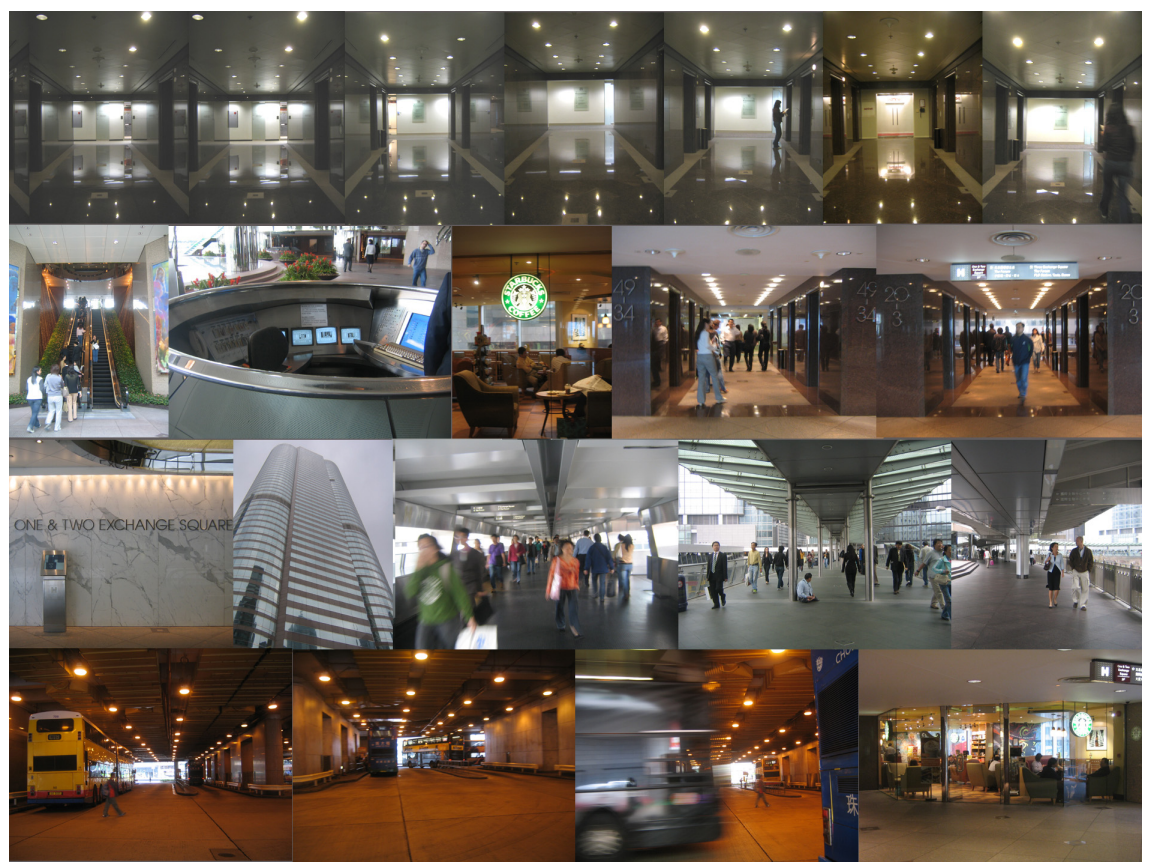

Figure 2: $\quad$ Exchange Square.

The development is home to many significant financial institutions such as the Hong Kong Stock Exchange, Citibank and Morgan Stanley etc. with the Hong Kong Monetary Fund in neighbouring IFC One. The recent completion of the IFC shopping centre and the Hong Kong Airport Express Station have introduced more activities to the area outside business hours, however the public open space is usually deserted from any activities outside normal business hours while adjoining elevated walkway moves consistent flow of pedestrians. With the heavily populated use of elevated walkways in Central, the ground level is almost deserted from any human activities or interaction. Highway - Connaugh Road - running adjacent to the development further isolates the development from pedestrians on ground level.

The Exchange Square Development typifies the vertical cul-de-sac commercial towers. The development permits entries by non-tenants during 
normal business hours, however strangers are always being watched through the eyes of 24-hour security guards and surveillance cameras installed in every conspicuous corner of the development. It is common for conventional cul-desacs to be terminated with a large open space, often in lollypop shapes which residents perceive as a safe place from high-speed traffic and hence suitable for children to play in. There are examples of towers with a more sociable termination, for instance, some apartment towers may have a communal rooftop garden, gym or clubhouse on top level and 64-storey commercial Hopewell Centre in Wan Chai, Hong Kong for example has a revolving restaurant on the top level which generates social activities different from that of conventional residential cul-de-sac. However, it has to be acknowledged that in the vertical version, more often than not, the end of the cul-de-sac is treated the same as all other levels. In Exchange Square Two, the top level is the same repeated floor plate as the one below. While a tenant occupying multiple levels may designate and therefore fit out the top floor as client and staff entertainment area, it does not invite strangers or other tenants for any social interaction.

\section{Conclusion}

Cities are growing bigger, higher and denser. A number of Chinese people equal to the Australian population are migrating to cities in China every year and this desire to move to cities is unlikely to cool down anytime soon. Through the experience in the west, cities aspire to grow in the vertical direction. From the examples presented here, it is clear that the current approach to the vertical cities can easily create similar conditions of horizontal sprawl - a kind of 'vertical sprawl'. Whether in vertical gated communities or vertical cul-de-sac developments, social and other activities are largely overshadowed by the enormity of identical floor plates repeated above podium levels. While this vertical aspiration may prevent cities from growing uncontrollably large in its footprint and therefore economically and environmentally be more sustainable in terms of land use and efficiency in provision of infrastructure, the social aspects is largely neglected. The planning approach with the two dimensional zoning facilitates extrusions of single program creating a vertical sprawl and therefore the current planning approach needs to be re-evaluated. More importantly the notion of the vertical city should be approached with attention to providing diversity and vitality through more intelligent stacking of diverse programs and reintroducing connections in multilevel and multi-directional manners.

\section{Acknowledgements}

This research is part of greater research for $\mathrm{PhD}$ at the University of Hong Kong and is also enabled by the Hazlet Bequest Scholarship from the University of Sydney. I would like to thank both Dr. Justyna Karakiewicz (University of Hong Kong) and Barrie Shelton (University of Sydney) for their advice in preparing this paper. 


\section{References}

[1] Mau, B. and the Institute without Boundaries, Massive Change, Phaidon Press Limited, pp. 37, 2004.

[2] Struik J., New South Wales in Focus 2005, Australian Bureau of Statistics, pp. 152, 2005.

[3] Newman, P. \& Kenworthy, J., Cities and automobile dependence, Gower Technical, Brookfield, VT, 1989.

[4] Newman, P. \& Kenworthy, J., Sustainability and cities, overcomes automobile dependence, Island Press, Washington, 1999.

[5] NSW Government, Metropolitan Strategy, NSW Department of Infrastructure and Natural Resources, Online, http://www.metro strategy.nsw.gov.au/dev/ViewPage.action?siteNodeId=75\&languageId=1 \&contentId $=-1$.

[6] Adam, H., Stacking and Layering, El Croquis, Vol. 111, pp. 31-38, 2002.

[7] Marquez, F. et al. ed., El Crouis, Vol. 111, pp. 172-183, 184-191, 2002.

[8] Mass, W. and Arets et al., W., 3D City, Hunch - The Berlarge Institute Report, No3, pp. 94-133, 2001.

[9] Attali, J, Vertical Labyrinths, Reading MVRDV, pp. 72-81, 2003.

[10] Karakiewicz, J.A., Poon Choi: A Multi-layer City - Dealing with overcrowding by intensifying the land use, International Symposium on City Planning 2004, Sapporo, 2004.

[11] Blakely, E. and Snyder, M, Fortress America: Gated Communities in the United States, Brookings Institution Press, 1997.

[12] Burke, M., The Pedestrian Behaviour of Residents in Gated Communities, Australia: Walking the $21^{\text {st }}$ Century Conference, Online, http://dpi.wa.gov.au/walking/pdfs/A14.pdf, 2001.

[13] Dovey, K., Safety and Danger in Urban Design, Safer Communities: Strategic Direction in Urban Planning Conference, 1998.

[14] Karakiewicz, J., Exploring the Dimensions of Urban Density, Royal Melbourne Institute of Technology, Unpublished Dissertation, Melbourne, 2002.

[15] Whittick, A. Encyclopedia of Urban Planning, Mcgraw-Hill Book Company, pp. 297, 1974.

[16] HongKong Land, Online, http://www.hkland.com/commercial property/ one two exchange square background.html. 